\title{
El desarrollo y las políticas públicas
}

\author{
Noelia Figueroa Burdiles \\ Universidad de Concepción, Concepción, Chile. Email: noeliafigueroa@udec.cl
}

\begin{abstract}
Resumen: Este ensayo examina la idea de “desarrollo” y su relación con políticas públicas que se han implementado en la segunda parte del siglo XX, a objeto de ofrecer miradas alternativas que superen las contradicciones que han operado en esta relación. Para ello, en la primera parte se revisa críticamente la noción de desarrollo como indicador de bienestar social, noción que ha orientado las políticas públicas implementadas en el período. En la segunda parte, el ensayo propone reconsiderar la esfera de "lo público", como mecanismo de superación de las contradicciones de las políticas del desarrollo. Finalmente, en la tercera parte se presenta la noción de territorio, como el espacio para la reconsideración de la idea del desarrollo y de la esfera pública. Ello, junto a nuevos enfoques del desarrollo que incluyan la interculturalidad, la conciencia ecológica y la subordinación del capital en la vida individual y social, podrían orientar perspectivas teóricas y empíricas que sustenten políticas públicas coherentes con las exigencias contemporáneas.
\end{abstract}

Palabras clave: desarrollo, lo público, políticas públicas, territorio.

\section{Development and public policies}

\begin{abstract}
This paper examines the idea of __development” and its relation to public policies that have been implemented in the second half of the twentieth century, seeking to offer alternative approaches to overcome the contradictions that have operated in this relationship. In order to do this in the first part we critically review the notion of development as an indicator of social welfare, notion which has focused public policies implemented in the period. In the second part, the paper proposes to reconsider the area of _"public" as a mechanism to overcome the contradictions of development policies. Finally, the third part presents the notion of territory as the space in which to reconsider the idea of _ development and of the public sphere. This, together with new approaches to development including interculturalism, ecologic conscience and subordination of capital in personal and social life, could guide theoretical and empirical perspectives that could support public policies consistent with contemporary requirements.
\end{abstract}

Key words: development, public field, public policies, territory.

\section{O desenvolvimento e as políticas públicas}

Resumo: Este artigo analisa a idéia de “desenvolvimento” e sua relação com as políticas públicas que têm sido implementadas na segunda metade do século XX, a fim de oferecer formas alternativas para superar as contradições que têm operado nesta relação. Para isso, na primeira parte faz uma revisão crítica da noção de desenvolvimento como um indicador de bem-estar social, uma noção que tem orientado as políticas públicas implementadas no período. Na segunda parte, o documento propõe repensar a esfera de "público" como um mecanismo para superar as contradições das políticas de desenvolvimento. Finalmente, a terceira parte 
apresenta a noção de território, como o espaço para uma reconsideração da idéia de desenvolvimento e da esfera pública. Isto, juntamente com novas abordagens para o desenvolvimento, incluindo o multiculturalismo, a consciência ambiental ea subordinação do capital na vida individual e social, poderia guiar perspectivas teóricas e empíricas para fazer políticas públicas de apoio consistentes com as exigências contemporâneas.

Palavras-chave: desenvolvimento, público, políticas públicas, território.

\section{El concepto de desarrollo}

La palabra desarrollo es un término que se usa en diferentes esferas, como verbo y/o sustantivo: desarrollar alguna actividad, el desarrollo de las personas, el desarrollo artístico. Pero no es un concepto que solo se refiera a la acción, sino que implica un aumento, una evolución, un progreso. El desarrollo es un concepto que se ha utilizado en la teoría económica, para indicar una medida de progreso de las sociedades occidentales en la organización de sus recursos y en las relaciones de intercambio de objetos materiales e inmateriales entre los sujetos que constituyen dichas sociedades. Objetos que serán valiosos en la medida que satisfagan las necesidades de dichos sujetos, y por lo tanto, contribuyan a su bienestar.

Es posible sostener que el concepto desarrollo en la esfera económica, comenzó a usarse cuando se inicia la discusión sobre la desigualdad entre los países del sur con respecto a los países del norte. La noción de subdesarrollo se aplica a los países del denominado tercer mundo, para referirse a la condición de aquellos países cuyo funcionamiento "se caracteriza por la inestabilidad y la dependencia; difícilmente puede romper el círculo vicioso de la pobreza” (Barre, 1958:16). Al revés, podríamos decir que un país desarrollado se caracteriza por su estabilidad e independencia, donde no existe pobreza. Un país o nación que es capaz de generar:

“un bienestar material, normalmente reflejado en el alza del ingreso real por habitante, y condicionado por la productividad del trabajo (...) lo que a su vez conlleva el aumento del capital por hombre ocupado. La mayor densidad de capital se va logrando a medida que la acumulación se lleva a cabo bajo el impulso del avance tecnológico, necesario para preservar márgenes de ganancia que aseguren la continuidad de la misma. (...) Así pues, consideradas en el mayor nivel de abstracción las ideas de desarrollo económico coinciden con las contenidas en líneas generales en las teorías del crecimiento de origen neoclásico y keynesiano (...)” (Rodríguez 2006: 54)

Luego de la segunda guerra mundial, se crea el sistema de Naciones Unidas, como mecanismo internacional para resguardar la paz mundial y promover el desarrollo; desde allí, específicamente la CEPAL (Comisión económica para América Latina), creada en 1948, se haría cargo de promo- 
ver políticas públicas de desarrollo económico para la región ${ }^{1}$. Los coletazos económicos generados por la guerra, la emergencia de la industrialización en América Latina ${ }^{2}$ y las concepciones keynesianas tendientes a fortalecer el papel del estado en las economías nacionales, son ingredientes adicionales para la expansión económica en la región.

El diagnóstico que hacían cientistas sociales latinoamericanos en los años 50 y que fundamentaba a la vez tal expansión, estaba construido en torno a las relaciones de dependencia que las economías de la región tenían con las economías del norte, lo que se denominó el sistema centro periferia (Rodríguez, 2006). A juicio de los estructuralistas, estas relaciones eran una de las causas principales del subdesarrollo. Para revertirlo, era necesario impulsar una estrategia de crecimiento económico por medio de la industrialización por sustitución de importaciones (Muñoz, 1986). Entonces, el crecimiento económico se constituyó en una reducción práctica del concepto de desarrollo, formando parte de la base ideológica de las políticas públicas de desarrollo durante la segunda mitad del siglo XX.

En coherencia con lo anterior, de acuerdo al análisis centro - periferia, el desarrollo logrado por las economías del centro (los países desarrollados), el progreso técnico y la acumulación de capital, se debía principalmente a un retraso inicial de las economías de la periferia, las cuales exhibían un modelo económico centrado en el desarrollo hacia afuera, es decir, en la exportación de bienes primarios, que no requerían grandes avances técnicos o de capital; mientras que el mercado interno de productos más elaborados era abastecido mediante las importaciones desde el centro. Un círculo vicioso, que mantenía una dinámica de desarrollo desigual, basada en relaciones de dependencia tecnológica, que se expresa en niveles de ingreso ostensiblemente inferiores.

Entonces, la superación de tal círculo vicioso debería enfocarse a las causas del sub-desarrollo, sobre todo en su componente "dependencia”, lo que fundamentaba los esfuerzos para favorecer el modelo de industrialización por sustitución de importaciones. Este modelo se constituía en "una opción privilegiada de cambio estructural, como el camino que permitiría transformar una estructura arcaica (el modelo de desarrollo hacia afuera) en una estructura moderna” (Muñoz 1986:97).

No obstante, las políticas impulsadas en torno a la industrialización, exhibirían síntomas de agotamiento a finales de la década del 60:

"La tecnología que América Latina tuvo que asimilar en la mitad del siglo XX es altamente ahorrativa de mano de obra y extremadamente exigente en lo que respecta a las dimensiones del mercado. Dentro de las condiciones presentes de América Latina la regla tiende a ser el monopolio o el oligopolio y una progresiva concentración del ingreso, la cual, a su vez, al condicionar la composición de la demanda, orienta las inversiones hacia ciertas industrias que son exactamente las de elevado coeficiente de capital y más exigentes en lo 
que respecta a las condiciones de mercado. La experiencia en América Latina ha demostrado que ese tipo de industrialización sustitutiva tiende a perder impulso al agotarse la fase de las sustituciones "fáciles” y provoca eventualmente el estancamiento”. (Furtado 1969:48).

De este modo, las políticas económicas impulsadas hasta la fecha no habían logrado su objetivo en torno a reducir la dependencia económica (y por lo tanto, avanzar en la senda del desarrollo), produciéndose un giro inesperado. El modelo de desarrollo hacia adentro había entrado en crisis y era necesario reconfigurar las economías de la región hacia un nuevo estilo de crecimiento económico que considerara la intensificación de las exportaciones. Las crisis políticas y la polarización ideológica de principios de la década del 70, derivaron en un cambio estructural de las bases económicas, centrado en la liberalización de las economías de los países de la región y la implementación de los programas de ajuste estructural impulsados por los organismos financieros internacionales. De algún modo, se volvía a un modelo de desarrollo hacia afuera como motor del crecimiento económico, con consecuencias políticas, sociales y económicas negativas para amplios sectores de la población.

Este nuevo modelo experimental, desarrollado principalmente en la década de los 80, perfeccionado en los '90 y continuado en este nuevo siglo, se basa en la hipótesis de que el crecimiento económico generará mediante un efecto en cascada ("teoría del chorreo”), mejoras en el bienestar de la población, indicadas principalmente por una distribución del ingreso generado por el aumento del capital y consecuentemente del empleo. Bajo esta hipótesis, se impulsaron una serie de políticas de cambio estructural asociadas a la reducción del tamaño del Estado, la liberalización comercial, las privatizaciones de empresas públicas, la apertura a la inversión extranjera, la desregulación económica, entre otras; permitiendo que el mercado, y sus “leyes” de oferta y demanda, se encargaran de la distribución del ingreso y la satisfacción de las necesidades de la población. Estas políticas redujeron los riesgos asociados a la inflación y el alto endeudamiento público que exhibían las economías de la región durante la década de los '80, pero no consiguieron los objetivos de desarrollo que supuestamente perseguían:

"la cara adversa fueron los resultados desalentadores en términos de crecimiento económico, reducción de la pobreza, redistribución del ingreso y condiciones sociales. En los años noventa, el aumento real del PIB en la región fue escaso; 1 por 100 anual durante toda la década, esto es, un porcentaje ligeramente superior a las alarmantes cifras registradas en los años ochenta, pero muy por debajo de las tasas del 5 por 100, o más, que se alcanzaron en los años 1960 y 1970. Concretamente, el desempleo aumentó, y la pobreza siguió siendo amplia y generalizada” (Casilda, 2004:24).

Como ha sido revisado precedentemente la noción de desarrollo ha sido objeto de diversas precisiones y recreaciones a nivel teórico y empíri- 
co, aunque continúa marcada por su origen (Arocena, 2002). La adopción de conceptualizaciones de desarrollo múltiples y contradictorias a los largo del periodo, ha tenido a nuestro juicio una lógica común, que se origina en los principios de la acumulación colonial y patriarcal en América Latina; mecanismos que han fomentado la consolidación de grupos de poder y de grupos al servicio de aquéllos. Y no es simplemente una cuestión política o moral, es un tipo de racionalidad basada en la dominación del hombre y de la naturaleza por el hombre; racionalidad que conquistó a Europa moderna y que se irradió hacia sus colonias en el tercer mundo, que formaron los países subdesarrollados. El subdesarrollo como categoría de análisis surgió entonces de la compresión de estas relaciones de explotación y de negación de las propias sendas de desarrollo, pero su conceptualización y aplicación a las políticas económicas de la época no fue capaz de transformar aquello que criticaba y que constituía la propia ideología del crecimiento económico, basada en una racionalidad económica de la acumulación capitalista-patriarcal-colonial que se sustenta en el dominio, a partir del establecimiento de un sistema - mundo basado en la colonialidad.

"Sólo con América pudo el capital consolidarse y obtener predominancia mundial, deviniendo precisamente en el eje alrededor del cual todas las demás formas fueron articuladas para los fines del mercado mundial. Sólo de ese modo, el capital se convirtió en el modo de producción dominante. Así, el capital existió mucho tiempo antes que América. Sin embargo, el capitalismo como sistema de relaciones de producción, esto es, el heterogéneo engranaje de todas las formas de control del trabajo y de sus productos bajo el dominio del capital, en que de allí en adelante consistió la economía mundial y su mercado, se constituyó en la historia sólo con la emergencia de América. A partir de ese momento, el capital siempre ha existido y continúa existiendo hoy en día sólo como el eje central del capitalismo, no de manera separada, mucho menos aislada. Nunca ha sido predominante de otro modo, a escala mundial y global, y con toda probabilidad no habría podido desarrollarse de otro modo" (Quijano, 2000³).

Siguiendo a Quijano, la configuración de los estados-nación en América Latina, suponía una sociedad imaginada parecida a Europa, concentrando el poder y sosteniendo las relaciones de dependencia no sólo económica sino también cultural. Esta dependencia llevó a los intelectuales del subdesarrollo y la dependencia a pensar desde las categorías establecidas por en centro. Aún cuando algunos autores como Cardoso y Faletto (1971) pensaban en la sociedad y cultura latinoamericanas como elementos claves para conducir a los países de la región al desarrollo; sus ideales, su sociedad imaginada estaba más cerca de Europa que de la América diversa y críptica, pues el cambio social requerido correspondía al paso de las sociedades tradicionales a las sociedades modernas en la región; modernidad que se alojaba en los centro urbanos, en las capitales, produciendo relaciones centro-periferia también al interior de los países, entre el sector rural indígena y campesino "atrasado", y la ciudad moderna. 
Estas contradicciones en la idea de desarrollo y los escasos efectos en el bienestar social de las políticas públicas asociadas a tal idea, hacen que pierda sentido y fuerza, y que aunque permanezca en pie, es necesario transformarla, puesto que "las luces que hacían resplandor la esperanza se han apagado. La gran empresa que, tanto en el Norte como en el Sur había comenzado tras la Segunda Guerra Mundial a fin de acelerar la consecución del desarrollo, está actual y definitivamente acabada” (G. Rist 2002, citado en Unceta 2009: 24).

Entonces ¿Cómo pensar una idea de desarrollo distinta a la que ha motivado el desempeño de los países latinoamericanos durante el siglo XX y que ha generado “culturas de centro” basadas en el crecimiento económico y el mercado, y “culturas periféricas” marginadas? ¿Es posible que una nueva conceptualización del desarrollo permita trascender las desigualdades intrínsecas del modelo económico adoptado por los países de la región? A nuestro juicio, hay dos elementos que contribuyen a pensar en ello: la resignificación de lo público y la noción de territorio.

\section{Lo público: de la acción del Estado a la participación social}

Vamos a entender lo público en tres sentidos básicos, que permiten diferenciar la esfera doméstica (donde los individuos resuelven sus necesidades básicas), de la esfera pública, es decir, del espacio donde la ciudadanía/comunidad ${ }^{4}$ libre resuelve asuntos comunes. Estos sentidos son "1) lo que es de interés o de utilidad común a todos, que atañe al colectivo, que concierne a la comunidad y por ende la autoridad de allí emanada (...) 2) lo que es visible y se desarrolla a la luz del día, lo manifiesto y ostensible (...) y, 3) (que puede resultar una derivación de los dos anteriores) lo que es de uso común, accesible a todos y por lo tanto abierto (...)” (Rabotnikof 1993:76)

Si bien en los países latinoamericanos la idea de lo público circunscrita a un Estado como autoridad, ha sido una cuestión más impuesta que acordada en el seno de la sociedad (Quijano, 2000), es posible decir que se trata de algo bastante difundido socialmente por lo menos en Chile. Así lo público se asocia a aquello que es de interés y utilidad común, que debe ser protegido en forma pública y se entiende que el mecanismo más apropiado para ello son las instituciones creadas por el estado, y la acción de ellas mediante políticas públicas. "En el uso habitual, las políticas públicas corresponden a la acción de una autoridad investida de poder público y de legitimidad gubernamental” (Lahera, 2008: 23). Esta definición supone un sistema democrático que otorga el poder público y la legitimidad al estado, su gobierno y sus instituciones.

Ahora bien, comprendiendo el debate que se origina en las nociones de democracia y legitimidad, que exceden este ensayo, la definición de políticas públicas expuesta también supone cierto centralismo en la protección del objeto público, si lo aplicamos a la concepción de gobernabilidad 
en el aparato del Estado-nación, como autoridad de poder público y legitimidad gubernamental. De allí, que muchas políticas públicas como las mencionadas en las sección precedente hayan respondido a objetivos del centro, más que reflejar la heterogeneidad del (os) territorio (s) país. Así, estas políticas dejaban fuera a partes importantes de la población; es más, eran comprendidas por esta población como acuerdos de las clases dominantes, que correspondían la mayor parte de las veces a grupos oligárquicos que buscaban acrecentar sus riquezas. Canciones de cantautores chilenos de esa época como Violeta Parra o Víctor Jara nos hablan de ello.

Estas desconfianzas relegan lo público, lo hacen inexistente; hay decisiones que son públicas, por el poder público de la autoridad, pero que no necesariamente son de beneficio público. Esta forma de concebir lo público profundiza las relaciones centro - periferia, que se expresan en la actualidad en la idea comúnmente usada "Santiago es Chile".

Por tanto, es necesario avanzar a una idea de lo público que se asiente en identidades locales. Lo público debiera emerger de un acuerdo democrático entre los agentes que participan en lo público, que entienden lo público, que viven lo público. Lo público puede ser una montaña, un curso de agua, una calle, una sede social, una fiesta tradicional. Así la esfera de lo público no es una abstracción, no corresponde a lo que unos pocos funcionarios de gobierno pueden hacer por los demás. Así la esfera de lo público se vuelve asible, abordable, aunque bajo la condición de que en las decisiones del uso y protección de lo público, sean tomadas bajo mecanismos de participación deliberativa del conjunto de sujetos que lo han definido.

Comprendido de esta forma lo público, se hace inabordable desde un estado unitario, desde el centro de poder hacia la periferia. En cambio, requiere distribuir el poder de decidir hacia la periferia, que en la medida que va empoderándose se convierte en un nuevo centro, en su propio centro.

Una política pública en tales circunstancias debe ser el resultado de la participación social y de la convergencia en aspectos de la vida en común que es necesario normar para la sana convivencia y la justicia. Una nueva concepción de la economía como el conjunto de mecanismos que hacen más eficiente la distribución y uso de los recursos disponibles territorialmente, la riqueza, para la satisfacción de las necesidades materiales e inmateriales, individuales y colectivas, trascendiendo los límites de la propiedad individual ${ }^{5}$. Corresponde a un nivel territorial, entendido el territorio como conjunto de identidades intersubjetivas y ecosistemas que sostienen la vida humana y natural.

\section{La noción de territorio, lo público y nuevos enfoques para el desarrollo}

Entenderemos por territorio una entidad compleja que se configura a partir de las subjetividades compartidas (identidades compartidas) de 
personas que habitan en un espacio geográfico determinado. Por tanto, en este espacio no es posible dividir lo material de lo simbólico, en tanto que corresponde a "um híbrido, formado da união indissociável de sistemas de objetos e sistemas de ações. Os sistemas de objetos, o espaço-materialidade, formam configurações territoriais, onde a ação dos sujeitos, ação racional ou não, vem instalar-se para criar um espaço” (Santos 1996, citado em Porto Gonçalves 2002: p.231).

También puede entenderse al territorio como un espacio biocultural (Rozzi et al, 2003) en construcción permanente que necesariamente requiere un conocimiento desarrollado sobre la diversidad biológica (biodiversidad) y de la convergencia de sus actores en torno a los sentidos del cuidado de los recursos comunes.

"Desde un punto de vista cognitivo, la existencia de la plétora de seres y procesos biológicos denotado por la palabra biodiversidad transcurren para nosotros en una interface biocultural, esto es, una relación dialéctica que emerge tanto de las propiedades biofísicas de los fenómenos observados como de las características de los lentes culturales del observador (/a)” (Rozzi: 52, el paréntesis es nuestro)

Definiciones interesantes del territorio desde el punto de vista ambiental y cultural, nos proveen los pueblos originarios (observadores de la naturaleza desde tiempos pre-coloniales), especialmente, de los testimonios recogidos en comunidades mapuche de la Araucanía: “el territorio para nosotros abarca desde donde nace el sol hasta donde el sol se pone” ${ }^{6}$.

Podríamos decir que esta afirmación, además de tener sentidos identitarios muy profundos, también comporta una raíz ecológica, ya que se acerca a la definición de cuenca ambiental ${ }^{7}$, como sistema biogeográfico en permanente interacción ecológica. Desde este punto de vista, es posible pensar en concepciones ambientales de territorio no solo en zonas rurales, caracterizadas por la predominancia de paisajes naturales, sino también en las ciudades, que muchas veces están instaladas en grandes cuencas que han dado origen a grandes valles. Mapocho, Bio Bio, Cautín, por mencionar algunos de los ríos que albergan ciudades en Chile.

Otro acercamiento al territorio, puede hacerse desde la identidad que le confieren las personas que habitan dicho espacio, que emana de una historia común, de sucesos sociales comunes, de una trama cultural común. No obstante, es necesario tener en cuenta que se trata de procesos de apropiación que son dinámicos y mutables, y que materializan en cada momento una determinada configuración social, una topología social (Porto Gonçalves 2002).

En este sentido, es posible aplicar a la noción de territorio, en tanto sistema, los principios de incertidumbre e irreversibilidad establecidos por la física cuántica, presentes en los sistemas dinámicos entendidos como 
“(...) sistemas inestables que se dirigen hacia un futuro que no puede ser determinado a priori porque tenderán a cubrir tantas posibilidades, como tanto espacio tengan a su disposición” (Prigogine, 1993:97; el subrayado es nuestro). Desde el paradigma de la complejidad, esto implica aceptar el enfoque posmoderno, en tanto se trata de trascender las lógicas mecánicas derivadas de una racionalidad instrumental, al servicio de objetivos individuales, hacia comprensiones de la realidad más complejas e interactivas entre actores que viven en un territorio. Se trata entonces de una construcción permanente, de territorios en movimiento y en interacción a escala mundial. Si bien las tendencias de la globalización tiende a homogeneizar las expresiones sociales o por lo menos provocar tensiones entre la esfera de lo local y lo global ${ }^{8}$, es posible encontrar en el territorio una escala local donde ocurren tales interacciones, y donde precisamente se hace necesario contrastar las diversas nociones de desarrollo.

Aquí entonces, cobra relevancia la idea de lo público y de cómo la noción de territorio como espacio común está más allá de la propiedad individual. Nuevas concepciones de desarrollo, asociadas a espacios comunes en territorios con características específicas, cuya población tiene necesidades también específicas, implican valoraciones distintas de la calidad de vida y de las habilidades que las personas comportan para resolver sus necesidades lo que "debe someterse al debate público como parte del proceso democrático de elección social” (Sen, 1998). Y este debate público debe darse a nivel territorial, descentralizando las políticas públicas que emanan desde autoridades centralizadas, orientadas a enfoques de desarrollo que son múltiples.

En esta diversidad de enfoques, interesa destacar en primer lugar las perspectivas indígenas del desarrollo que han expresado sujetos indígenas que han emergido durante las últimas dos décadas ${ }^{9}$. Estas perspectivas se sostienen en el idioma Mapudungun, que exhibe un sinnúmero de ideas, conceptos, símbolos y sentidos que configuran una forma particular de concebir las relaciones sociales y la vinculación del ser humano con la naturaleza ${ }^{10}$. Algunos de estos conceptos pueden encontrarse en la siguiente cita:

"Lo primero que queremos decir es que el concepto de Desarrollo ha sido instalado desde la lógica occidental. Para nosotros no existe ese concepto, existe una idea distinta, que parte desde el ser persona, desde ahí comenzamos a configurar los planos económico, social y ambiental (...). El desarrollo lo vemos en forma multidimensional, donde esté presente lo material y lo espiritual. No consideramos Desarrollo proyectos que promueven la iniciativa individual, disociando el colectivo (...). Nos mueve el Küme Mognen, el "vivir bien". Para nosotros las diferentes formas de vida que conviven en un espacio, proveen bienestar a quienes lo habitan y protegen (...). Siempre partiremos desde el Kïmün ${ }^{11}$ y Rakiduam $^{12}$ mapuche, desde miles de años de sabiduría. Esto nos han permitido interpretar la naturaleza a través de otro concepto que quisiéramos 
compartir, el Ixofil Mognen ${ }^{13}$ (...) que representa la coexistencia de diferentes formas de vida que se necesitan mutuamente para mantener el sentido de territorio que apreciamos como Mapuche, por tanto debe ser protegida y conservada" (citado en Figueroa et al 2005: 21).

Sin querer reducir este texto, es posible observar en él un tipo de desarrollo que pone al centro al sujeto-persona-nosotros y su relación con la naturaleza y con lo espiritual; las riquezas como materialidad e inmaterialidad, y donde los sentidos y recursos comunes están al servicio de la protección y conservación del territorio, que es reconocido por quienes lo habitan, y donde es central la convergencia y lo colectivo en la producción de prácticas vernáculas y en el diseño y realización de acciones públicas. Esta cosmovisión conduce la actividad y la creación humanas. Cosmovisión que puesta en diálogo y práctica intercultural ${ }^{14}$, permitiría desarrollar una conciencia ecológica, que implique una nueva racionalidad en las relaciones humanas y con la naturaleza. Mara Rosas Baños en la proposición de una economía ecológica, sostiene que ello solo será posible a través de formulaciones teóricas que estén basadas en una racionalidad ambiental, como la que exhiben comunidades rurales, que haga frente a los problemas ecológicos derivados de una sociedad que subsiste "despilfarrando los recursos de las futuras generaciones y extinguiendo todo lo que represente una ganancia económica” (2010).

Cercana a esta vertiente, otra perspectiva interesante con respecto al desarrollo también radical en la exposición de su oposición al paradigma que cimenta las nociones de desarrollo revisadas anteriormente, es la teoría del "decrecimiento sostenible”. Esta teoría sostiene que los recursos y la capacidad productiva actuales son suficientes para satisfacer las necesidades de la población del planeta y que el problema estriba en la mantención de estilos de vida de alto consumo energético y poco sustentables (economías desarrolladas), y una mala distribución de la riqueza a nivel mundial. Esto implica que los países desarrollados ya no serían el modelo; al contrario, en las economías tradicionales existirían una serie de conocimientos que es posible revalorar para un uso más eficiente de los recursos. La frase “vivir mejor con menos” sintetiza estas ideas ${ }^{15}$. Por lo tanto, políticas públicas deberían enfocarse a estos dos problemas, potenciando así una nueva visión de desarrollo.

"El decrecimiento en el contexto de una sociedad occidental opulenta no debe ser visto como una merma del nivel actual de bienestar, sino como una oportunidad de aumentarlo. Eso sí, entendiendo el bienestar no como un concepto cuantitativo, basado en una acumulación infinita de bienes materiales, sino como un concepto cualitativo donde prime el tiempo de ocio, las relaciones humanas, la equidad, la justicia o la espiritualidad. Todo ello, bajo la tutela de una sociedad autolimitada (...), o en palabras de Sachs (1999), una sociedad capaz de no desear cosas que es capaz de proveer'.” (Bermejo et al 2010: 23) 
Quisiera complementar esta última perspectiva, con las proposiciones del filósofo André Gorz (1998) sobre la multiactividad en su libro "Miserias del presente, riqueza de lo posible". Este autor nos invita a crear "nuevas relaciones sociales sustraídas de la lógica del mercado, del dinero, de la división sexual de tareas; nuevos espacios temporales sustraídos al salariado; nuevas técnicas de producción y nuevas relaciones con el medioambiente que se preocupen por los equilibrios naturales y las otras formas de vida, etcétera. Y en el corazón de todo eso, la reapropiación individual del tiempo y de la organización del tiempo” (Ibid: 90)

Al comprender al ser humano como un agente multiactivo, entendemos que el bienestar no pasa solamente por obtener un ingreso monetario para la satisfacción de necesidades. Se entiende que el ser humano requiere de otras cuestiones que ni el mercado ni una visión monetarista del bienestar pueden otorgar. Comprender la multiactividad humana, como creación y creatividad; como forma de bienestar que implica “(...) desplazar el eje de gravedad de la vida de todos, de manera tal que la empresa y el trabajo con fines económicos no ocupen más que un lugar subordinado" (op.cit. :112).

\section{Conclusión}

Existe acuerdo que la acción pública y las transformaciones sociales y económicas en América Latina y Chile del siglo XX conducidas bajo el discurso del desarrollo, no han promovido en la región una mejor distribución de la riqueza natural y producida. Al contrario. Por ello, a nuestro juicio, es fundamental avanzar en la superación de los paradigmas que han conducido sistemas políticos y económicos basados en la noción de desarrollo, que presenta claras señales de agotamiento.

Si aceptamos que la acción pública mediante políticas redistributivas construidas democráticamente, puede ser un mecanismo para alcanzar el bienestar social, ello será posible solo si tales políticas se definen territorialmente. Esto implica la resignificación de lo público en un espacio territorial determinado, con sujetos situados para el uso y protección de lo que es de interés común en dicho territorio. La introducción de nuevas perspectivas de desarrollo que trasciendan su reducción al mero crecimiento económico, permiten, a nuestro juicio, transformar la matriz ideológica que ha conducido las políticas asociadas en los últimos 60 años.

Algunas de estas perspectivas son la promoción de una conciencia ecológica que oriente un uso menos depredador de los recursos naturales y una distribución más equitativa; la puesta en valor las cosmovisiones y prácticas de los pueblos originarios y las comunidades rurales; y la colocación del capital en un lugar subordinado de la vida individual y social.

Estas perspectivas juntas, a nuestro juicio, permiten análisis transformadores, y abren las posibilidades para trabajar desde un enfoque terri- 
torial y de convergencia social, que se oriente a la superación de las nociones del desarrollo prevalentes, transitando hacia unas que contemplen las especificidades de la diversidad social, cultural y natural.

Para ello, desde la academia, es necesario abordar esta materia a través de comunidades inter y transdisciplinarias que incluyan la interculturalidad como apertura a la diversidad de perspectivas y subjetividades compartidas, en una creciente integración e interacción ecológica de la academia con los territorios que la sustentan. Desde allí, será posible influir en el diseño e implementación de políticas públicas descentralizadas que contribuyan al bienestar humano, social y natural como indicadores situados de desarrollo, en una época que lo exige crecientemente. 


\section{Notas}

${ }^{1}$ Es importante señalar que Raúl Prebisch escribiría en 1949 para la CEPAL "El desarrollo económico de la América Latina y algunos de sus principales problemas", un artículo fundacional que dio inicio a la teorización cepalina, por donde pasaron destacados economistas latinoamericanos, como Celso Furtado, Aníbal Pinto, Osvaldo Sunkel, entre otros. En CEPAL (1998)

${ }^{2}$ En Chile, un poco antes se crea la Corporación nacional de fomento, CORFO, institución estatal destinada a impulsar el Plan de fomento industrial, que incluía el desarrollo de las industrias metalúrgica, textil, química y afines, maderera y pesquera, junto con el fomento a la enseñanza técnica. En CORFO (1939).

${ }^{3}$ Referencia disponible en Internet: http://bibliotecavirtual.clacso.org.ar/ar/libros/lander/ quijano.rtf

${ }^{4}$ Usamos la díada ciudadanía/comunidad para dar cuenta de espacios distintos: la urbe y lo rural.

${ }^{5} \mathrm{Si}$ bien no deseo entrar en un análisis dialéctico entre lo público y lo privado, considero que cuando las personas construyen intersubjetivamente una noción de territorio (por ejemplo, lo que ha sucedido con la oposición pública al proyecto hidroeléctrico Hidroaysén que pretende afectar amplias zonas de la Patagonia en Chile), trascienden de la noción de propiedad individual, es decir, no importa tanto quien o quienes sean propietarios del territorio, sino más bien lo que importa son las valoraciones intersubjetivas que se hacen de él. Ahora esta es una tesis que me gustaría desarrollar en trabajos posteriores.

${ }^{6}$ Me permito recurrir a la oralitura, como dice el poeta Elicura Chiguaylaf, a partir de mi experiencia: entre los años 2003 y 2006 participé en un proyecto de cooperación belga a organizaciones territoriales mapuche, que concluyó con la publicación de un libro llamado “Aprendizajes para la autogestión territorial mapuche” (en bibliografía) donde se sistematizaron las ideas acerca del territorio y del desarrollo desde la perspectiva indígena. Además, durante los años 2007 y 2008 viví en una comunidad mapuche donde escuché esta frase sobre la definición de territorio.

${ }^{7}$ Si bien hay distintas perspectivas para definir este concepto, aceptamos la definición realizada por Romero et al (2003) "Un sistema semicerrado, que otorga un carácter esencialmente endógeno a los flujos atmosféricos, hídricos, geomorfológicos y biogeográficos que se desarrollan en su interior (...)" "los valles fluviales que originan las cuencas están enmarcados por montañas y relieves que se despliegan extensamente en sus nacientes y se reducen significativamente en los exutorios” (174).

${ }^{8}$ La acción de las transnacionales es un ejemplo de ello.

${ }^{9}$ Un amplio desarrollo puede encontrarse en "Propuestas de organizaciones territoriales mapuche al Estado chileno” Pegun 2006, presentadas en 2007 a la presidenta Michelle Bachelet. Disponible en Internet. http://www.wenewenche.cl/anterior/central/noticias/ 702041/Propuesta_organizaciones_mapuches.pdf

${ }^{10}$ Existen varios proyectos doctorales de investigación asociados a la lengua mapuche en la Universidad de Concepción. Uno en particular, de la doctorando Damsi Figueroa, indaga 
en estos conceptos propios del mapudungun relacionados con la vinculación del ser humano con la naturaleza, a través del análisis de poesía mapuche.

${ }^{11}$ Sistemas de conocimiento originario

\section{${ }^{12}$ Pensamiento}

${ }^{13}$ Biodiversidad en un sentido amplio

${ }^{14}$ Entendiendo la interculturalidad como el proceso mediante el cual nos abrimos al diálogo como creación de un espacio de interacción determinado por la convivencia; transfigurando lo propio y lo ajeno, subordinando si se quiere la propia cultura o por lo menos cuestionando el punto de partida como "observador"; visibilizando los paradigmas que la sustentan y abriéndose a la posibilidad de adquirir y/o crear nuevos conocimientos en ese espacio de interacción, valorando la capacidad reflexiva y racionalidad práctica del interlocutor(a) (Salas, 2006).

${ }^{15}$ Una aplicación la práctica de "vivir bien con menos", es el uso de materiales que la biósfera es capaz de renovar, fundamentalmente aquéllos que se ubican en la corteza terrestre (Naredo \& Valero, 1999). 


\section{Bibliografía}

Arocena, José (2001), “Globalización, integración y desarrollo local. Apuntes para la elaboración de un marco conceptual”. En Transformaciones globales, Instituciones y Políticas de desarrollo local. Madoery, Oscar y Vázquez Barquero, Antonio (eds.) Editorial Homo Sapiens, Rosario.

Bachelard, Gaston (2004), La formación del espíritu científico. Contribución a un psicoanálisis del conocimiento objetivo. $25^{\circ}$ edición (1948, $1^{\circ}$ ed. Español). Editorial Argos - Siglo XXI Editores, México.

Barre, Raymond (1958), El desarrollo económico. Fondo de cultura económica, México.

Bermejo, Roberto, Arto, Iñaki, Hoyos, David y Garmendia, Eneko (2010), "Menos es más: del desarrollo sostenible al decrecimiento sostenible”. En Cuadernos de Trabajo de Hegoa Número 52, Julio 2010, Universidad del País Vasco, España.

Casilda, Ramón (2004), “América Latina y en consenso de Washington”. En Boletín Económico de ICE N²803, del 26 de abril al 2 de mayo de 2004, España. Disponible en la web: www.revistasice.com .

CEPAL (1998), CEPAL Cincuenta Años. Reflexiones sobre América Latina y el Caribe. Revista de la Comisión Económica para América Latina y El Caribe (CEPAL), número extraordinario, publicación de las Naciones Unidas, octubre 1998, Santiago.

Cardoso, Fernando y Faletto, Enzo (1971), Dependencia y desarrollo en América Latina. Ensayo de interpretación sociológica. $3^{\circ}$ edición. Siglo XXI Editores, México.

CORFO (1939), Plan de Fomento Industrial, Corporación de Fomento a la Producción, Chile. Disponible en la web: www.memoriachilena.cl

Figueroa, Noelia (2005), Aprendizajes para la Autogestión Territorial Mapuche: Experiencias de cinco organizaciones territoriales indígenas. Con la colaboración de representantes de la Asociación Ñankuchew, la comunidad Felipe Punolef, la Asociación Pulafkenche la asociación Mapuhual y FONDS VOOR ONTWIKKELINGSSAMENWERKING, FOS Bélgica \& Chile. Edición FOS, Concepción.

Furtado, Celso (1969), Estancamiento y subdesarrollo en América Latina. 2da. Edición, Editorial Universitaria de Buenos Aires, Argentina.

Gorz, André (1998), Miserias del presente, riqueza de lo posible. Traducción del francés de Cristina Piña. Editorial Paidós SAICF, Buenos Aires.

Lahera, Eugenio (2008), Introducción a las políticas públicas. $2^{\circ}$ edición. 
Fondo de Cultura Económica, Santiago.

Muñoz, Oscar (1986), Chile y su industrialización. Pasado, crisis y opciones. CIEPLAN Ediciones, Santiago.

Naredo, J.M. \& Valero, A. (1999), Desarrollo económico y deterioro ecológico. Fundación Argentaria - Visor Dis, Madrid.

Porto Gonçalves, Carlos Walter (2002) “Da geografia às geo-grafias: um mundo em busca de novas territorialidades” En La guerra infinita: Hegemonía y terror mundial. Ceceña \& Sader (comp). CLACSO, Buenos Aires

Prigogine, Ilya (1993), El nacimiento del tiempo. $2^{\circ}$ edición. Colección Metatemas, libros para pensar la ciencia, Tusquets Editores, España.

Quijano, Aníbal (2000), ”Colonialidad del poder, eurocentrismo y América Latina”. En La colonialidad del saber: eurocentrismo y ciencias sociales. Perspectivas Latinoamericanas. Edgardo Lander (comp.) CLACSO, Consejo Latinoamericano de Ciencias Sociales, Buenos Aires. p. 246. Disponible en la web: http://bibliotecavirtual.clacso.org.ar/ar/libros/lander/ quijano.rtf

Rabotnikof, Nora (1993), "Lo público y sus problemas: notas para una reconsideración”. En Revista Internacional de Filosofía Política, Universidad Autónoma Metropolitana, México. Disponible en la web: http://espacio.uned.es:8080/fedora/get/bibliuned:filopoli-1993-2-C04E1B1FB9D9-F0CB-DF7D-185DF6E5C990/publico_problemas.pdf

Rodríguez, Octavio (2006), El estructuralismo latinoamericano. Editorial Siglo XXI - CEPAL, México.

Romero, Hugo; Ordenes, Fernando; Vásquez, Alexis (2003), “Ordenamiento territorial y desarrollo sustentable a escala regional, ciudad de Santiago y ciudades intermedias en Chile" Capítulo VI de Globalización y biodiversidad: oportunidades y desafíos para la sociedad chilena. Figueroa, E. \& Simonetti, J. Editores. Editorial Universitaria S.A., Santiago.

Rosas Baños, Mara (2010), “Propuesta teórica para enfrentar los retos del siglo XXI: Economía ecológica política”. Revista Sustentabilidad(es) ISSN 0718-8854, Santiago; versión en línea. Disponible en la web: http:// www.sustentabilidades.org/revista/publicacion-01/propuesta-teorica-paraenfrentar-los-retos-del-siglo-xxi-economia-ecologica-politica

Rozzi, Ricardo; Massardo, Francisca; Silander, John; Anderson, Christofer \& Marin, Andrés (2003), “Conservación biocultural y ética ambiental en el extremo austral de América: Oportunidades y dificultadas para el bienestar ecosocial” Capítulo II de Globalización y biodiversidad: oportunidades y desafíos para la sociedad chilena. Figueroa, E. \& Simonetti, J Editores. Editorial Universitaria S.A., Santiago. 
Salas, Ricardo (2006), Ética Intercultural. Ensayos de una ética discursiva para contextos culturales conflictivos. (Re) Lecturas del pensamiento latinoamericano. Ediciones Abya Yala, Ecuador.

Sen, Amartya (1998), “Teorías del Desarrollo a principios del Siglo XXI”. En Cuadernos de Economía, v. XVII, n. 29, Bogotá, 1998, páginas 73100. Universidad Nacional de Colombia.

Unceta, Koldo (2009), “Desarrollo, Subdesarrollo, Maldesarrollo y Postdesarrollo. Una mirada transdisciplinar tras el debate y sus implicancias”. En Carta Latinoamericana N7, editorial del País Vasco, España.

Wright, Ronald (2006), “Breve historia del progreso, ¿Hemos aprendido por fin las lecciones del pasado”. Traducción del inglés de J. A. Bravo. Ediciones Urano S.A. de Barcelona, España.

Recibido: 11.02.12

Aceptado: 16.08.2012 